\title{
PROPOSTA DE IMPLEMENTAÇÃO DE MÉTODOS E SISTEMAS DE GESTÃO PARA APERFEIÇOAR OS PROCESSOS INTERNOS DE UMA EMPRESA DE VAREJO: ESTUDO DE CASO LOJA SHOP SUKATÃO
}

\section{ARTIGO ORIGINAL}

REIS, Emelir Coelho dos ${ }^{1}$, SOUZA, Elisnanda Ewelly Ribeiro de ${ }^{2}$, SOUZA, Raquel Elpidia Siqueira de ${ }^{3}$, OLIVEIRA, Daniel Barroso de ${ }^{4}$, ALMEIDA, Victor da Silva ${ }^{5}$, LEITE, Ygor Geann dos Santos ${ }^{6}$, ROBERTO, José Carlos Alves ${ }^{7}$

REIS, Emelir Coelho dos. Et al. Proposta de implementação de métodos e sistemas de gestão para aperfeiçoar os processos internos de uma empresa de varejo: Estudo de caso Loja Shop Sukatão. Revista Científica Multidisciplinar Núcleo do Conhecimento. Ano. 06, Ed. 11, Vol. 10, pp. 27-46. Novembro 2021. ISSN: 2448-0959, Link de acesso: https://www.nucleodoconhecimento.com.br/administracao/metodos-e-sistemas, DOI: 10.32749/nucleodoconhecimento.com.br/administracao/metodos-e-sistemas

\section{RESUMO}

O presente estudo de caso realizado na loja de variedades shop sukatão pretende apresentar alternativas para solução dos problemas operacionais identificados no diagnóstico organizacional realizado na organização. Neste contexto, tem como questão norteadora: Como a reestruturação dos fatores internos pode maximizar o

\footnotetext{
${ }^{1}$ Graduando do curso de Administração.

${ }^{2}$ Graduando do curso de Administração.

${ }^{3}$ Graduando do curso de Administração.

${ }^{4}$ Coorientador. Bacharel curso de Administração.

${ }^{5}$ Coorientador. Mestre em Engenharia de Processos. Pós-Graduando em Neuropsicopedagogia Institucional. Especialista em Gestão Estratégica de RH. Graduado em Administração e Pedagogia.

${ }^{6}$ Coorientador. Mestre em Ciência e Engenharia de Materiais. Especialista em Engenharia da Qualidade e Seis Sigma. Graduado em Tecnologia em Gestão da Qualidade.

${ }^{7}$ Orientador. Mestre em Engenharia de produção. Especialista Logística empresarial. Graduado em Administração com Ênfase em Marketing.
}

RC: 101642

Disponível em: https://www.nucleodoconhecimento.com.br/administracao/metodos-esistemas 
desempenho operacional de uma empresa de varejo? Objetivo geral foi apresentar uma proposta de maximização do desempenho através da implementação de sistemas e métodos nos processos operacionais da loja varejista objeto do estudo de caso. A metodologia utilizada foi a pesquisa qualitativa, de campo e exploratória. Com a finalidade de propor resultados desejados, utilizando a ferramenta $5 \mathrm{~W} 2 \mathrm{H}$, foram elaborados quadro de ações interventivas, que forneceram direcionamentos para o estudo, otimizando a solução dos problemas, como: a frequência na compra de produtos e materiais, prazo de entrega dos produtos, normatização e padronização da entrega de produtos, proporcionando, assim, soluções através da Implementação do método Balanced Scorecard - BSC, da ferramenta Material Requirements Planning (MRP), do método SCRUM, da ferramenta 5'S e do Sistema Omnichannel. Considera-se que, dessa maneira, os resultados esperados para as necessidades da sejam atingidos e, a organização, possa obter mudanças satisfatórias no setor de operacional e de produção, alcançando seus objetivos sejam alcançados de forma a promover o crescimento da organização.

Palavras-chave: Operações, Indicadores de Desempenho, Processos internos, Metas.

\section{INTRODUÇÃO}

O presente artigo tem a intencionalidade de propor a implementação de sistemas e métodos para otimizar os fatores internos e externos na área operacional em uma empresa de varejo. Para isto, foi realizado um estudo de caso na Loja Shop Sukatão, cuja empresa é uma organização que atua no comércio varejista, no ramo de variedades.

O setor operacional da empresa é responsável por diversas atividades, dentre elas: logística, gestão de recursos de materiais, vendas e operações. Mediante as análises e pesquisas baseadas no diagnóstico realizado na empresa, observou-se que o setor operacional é a área mais crítica. 
Segundo Menezes (2018), é no planejamento operacional que se executam as ações traçadas pelo nível tático, para atingir os objetivos das decisões estratégicas.

A partir dos problemas identificados na organização, definiu-se como questão norteadora: Como a reestruturação dos fatores internos pode maximizar o desempenho operacional de uma empresa de varejo?

Objetivo geral foi apresentar uma proposta maximização do desempenho através da implementação de sistemas e métodos nos processos operacionais da loja varejista objeto do estudo de caso.

Como objetivos específicos o estudo de caso buscou identificar as ações interventivas que poderiam maximizar os resultados da organização, de acordo com as características da empresa estudada e propor um conjunto de ações que direcionam a organização na busca por melhores resultados operacionais.

O método utilizado foi o qualitativo, onde a coleta de informações foi essencial. Quanto aos fins, a pesquisa, foi exploratória, onde obteve-se uma visão geral acerca da situação encontrada, realizando um estudo mais aprofundado a fim de encontrar uma solução para o problema identificado. Quanto aos meios, a pesquisa de campo apresentou: coleta de dados, análise e observação.

Ao verificar a situação da empresa referente quanto ao setor operacional, foi sugerido como solução, a implementação de alguns programas, como: Balanced Scorecard, Material Requirementes Planning (MRP), Scrum, Ferramenta 5S, e o Sistema Omnichannel, visando a maximização dos resultados operacionais, a valorização dos clientes e colaboradores, oferecendo qualidade em seu atendimento, serviço de entrega e bom preço. 


\section{REVISÃO BIBLIOGRÁFICA}

A fundamentação teórica consiste em realizar uma revisão de trabalhos já existentes sobre o tema abordado, identificando o grau de importância e a estrutura conceitual (PEROVANO, 2016).

De acordo com Perovano (2016), a revisão permite a identificação de questões e temas, bem como a verificação de assuntos ainda não pesquisados.

Portanto, a fundamentação teórica consiste, de forma geral, na revisão das pesquisas e discussões de outros autores sobre o tema que será abordado no trabalho. Ou seja: é a contribuição das teorias de outros autores para a pesquisa.

\subsection{MÉTODO BALANCED SCORECARD}

O Balanced Scorecard (BSC), teve seu surgimento no ano de 1992, por meio de um artigo - "The Balanced Scorecard - Measures That Drive Performance" - publicado na Harvard Business Review, por Robert Kaplan e David Norton, (SILVA 2017). O artigo descrevia sobre um sistema de alinhamento do controle estratégico da gestão, permitindo às empresas identificar os indicadores financeiros e os processos internos.

Para Silva (2017), o método Balanced Scorecard (BSC), identifica os resultados dos processos das empresas a fim de discernir as causas e efeitos que impelem todos os âmbitos e os fatores externos e internos. Este método, possibilita, também, a identificação dos indicadores financeiros de forma ampla gerando a empresa viabilidade de crescimento.

Segundo Cardoso (2016), pode-se dizer que o BSC tem por finalidade avaliar o desempenho da organização, identificando os fatores importantes para implementação de ferramentas asseguradas para os resultados esperados através do planejamento estratégico. 
O Balanced Scorecard direciona os gestores à visualização dos objetivos estratégicos da organização através de planejamento estratégico, possibilitando a detecção dos fatores internos e externos, aliados aos indicadores de desenvolvimento, direcionando as ações para o alcance das metas empresariais.

\subsubsection{MATERIAL REQUIREMENTS PLANNING (MRP)}

O Planejamento das Necessidades de Materiais ou Material Requirement Planning MRP, foi desenvolvido na década de 1970 (MENEGAT; BORELLAO, 2017). É um sistema desenvolvido para planejamentos de compra e produção. Tem como principal objetivo o gerenciamento do controle de estoque, de insumos e a quantidade de itens a serem comprados.

Segundo Menegat e Borellao (2017), O MRP, busca manter o mínimo de quantidades de estoque, ou seja, manter apenas o que é necessário para a produção até a entrega final do produto, sem que ocorram atrasos na entrega, provendo ganhos nos custos e incrementando os recursos de manufatura da empresa.

Segundas ideias de Menegat e Borellao (2017), o sistema Material Requirement Planning - MRP, tem sua contribuição na armazenagem de custo, otimizando as compras feitas pela empresa. Sendo assim, determina os números de estoque, até mesmo de lotes econômicos, tornando a forma de administrá-los por produtos ou lead time.

De acordo com Martelli e Dandaro (2015), no gerenciamento do estoque ou de controle, é necessário a análise, quanto aos recursos materiais, de quando e onde colocá-los, visando o maior controle deles. Através da armazenagem, os produtos serão otimizados para processos de crescimento e competitividade da organização.

O Planejamento das Necessidades de Materiais (MRP), é o instrumento de planejamento para as organizações, que desenvolve o controle de estoque de acordo com os processos do produto, gerando para a empresa a redução de custos

RC: 101642

Disponível em: https://www.nucleodoconhecimento.com.br/administracao/metodos-esistemas 
e uma produção eficaz, ampliando os melhores sistemas de gestão dentro da organização.

\subsection{MÉTODO SCRUM}

O programa Scrum foi criado em 1989, e a partir daí, enfatizado por Ken Scwaber e Jeff Sutherland em 1993. O programa teve origem baseada na famosa jogada de Rugby, onde todos da equipe se juntam reiniciando uma jogada com o objetivo de retomar a posse de bola, até chegar ao objetivo. O Scrum é um processo baseado em experiências vividas por seus criadores e autores, algo totalmente empírico e que trará o resultado almejado (IEEP, 2020).

Para Duarte (2021) "Scrum é um framewok leve que ajuda pessoas, times e organizações, a gerar valor através de soluções adaptativas para problemas complexos."

Segundo Scwaber e Sutherland (2013) o Scrum é um framework no qual pessoas podem tratar e resolver problemas, ao mesmo tempo que produzem e entregam produtos com alto valor. Ao se aplicar o software na empresa e adequar o programa, é de suma importância definir o passo a passo. Para implementar o Scrum é preciso:

1. Escolher um Product Owner - a pessoa responsável por esta nova visão, o dono do projeto. Ele deverá levar em consideração os riscos e benefícios, as possibilidades cabíveis como, também, descobrir qual a motivação da equipe que trará paixão pelo serviço e, principalmente, atenderá as necessidades do cliente.

2. Escolher uma equipe - pessoas que vão entender o projeto e aderir a visão do responsável.

3. Escolher um Scrum Master - Semelhantemente ao PO, é a pessoa responsável por todo o projeto Scrum. Semelhante a um grande maestro, será quem irá orientar a equipe em toda a estruturação de processos do programa. 
4. Criar um Product Backlog - Como um mapa que leva ao seu destino, esta é uma lista com tudo que deverá ser executado. É o segredo para um atendimento de excelência aos clientes, ao mesmo tempo em que irá consultar os stakeholders e a equipe, para entender o que de fato precisa ser construído.

5. Elaborar as estimativas do Product Backlog - As estimativas (previsões) do projeto deverão ser elaboradas pela equipe, sempre analisando a realidade de seus clientes e da empresa.

6. Planejar o Sprint - é a primeira reunião do Scrum, com todos os envolvidos a fim de verificar a durabilidade do projeto e detalhes a serem definidos.

7. Tornar o trabalho visível - criação de um Scrum Board ou Kanban, uma tabela com 3 colunas contendo os seguintes itens: a fazer, fazendo e feito.

8. Daily Scrum (Reunião Diária) - todos os dias e no mesmo horário, a equipe e seus líderes se reúnem para responder a três questões: o que você fez ontem, o que vai fazer hoje e se existe algum impedimento para a equipe concluir o objetivo do Sprint.

9. Sprint Review ou Demonstração do Produto - uma reunião aberta ao público interessado (clientes, stakeholders e gestores), onde serão apresentados os resultados do projeto e que poderão ser realmente entregues aos clientes.

\subsubsection{S}

O 5's é a junção de cinco palavras japonesas que são utilizadas como ferramentas para organizar as empresas, aplicando hábitos e valores culturais que normatizam a empresa, trazendo satisfação aos clientes e podendo, também, ser aplicado em qualquer tipo de organização. Desta forma, os colaboradores, tornam-se mais produtivos e comprometidos com o trabalho a ser realizado.

O significado de cada S é: Seiri (utilização), Seiton (organização), Seiso (limpeza), Seiktsu (padronização), Shitsuke (disciplina). 
Para Minetto (2018) as cinco palavras japonesas são conhecidas como "senso", que significa discernimento, raciocínio e atenção.

Para Leão (2021), o 5S, é um programa de gestão que melhora a empresa em diversos pontos, dentre eles: a limpeza, organização e padronização.

Esta ferramenta reduz os desperdícios e otimiza os processos na empresa, em todos os setores, provoca mudanças comportamentais e torna-a mais limpa e organizada, com os materiais bem-posicionados.

Para a empresa em questão, ao aplicar esta ferramenta como um de seus mecanismos de trabalho, haverá a mudança desejada e o resultado para se alcançar os objetivos propostos será bem mais rápido, trazendo os seguintes benefícios:

1. Aumento da qualidade dos produtos;

2. Aumento da produtividade da equipe;

3. A empresa estará mais bem preparada para implementar outras metodologias de qualidade e produtividade;

4. Identificação de falhas e pontos de melhoria no processo;

5. Prevenção de acidentes no ambiente de trabalho;

6. Melhora no ambiente e qualidade do trabalho;

7. Ambiente mais organizado e padronizado para a implementação de certificações, como a ISO 9001.

\subsection{SISTEMA OMNICHANNEL}

Com os avanços tecnológicos e as mudanças nos padrões de consumo, o varejo tem se tornado cada vez mais competitivo. A maior integração entre os diferentes canais de contato entre o consumidor e o ponto de venda, possibilitou a criação de novas experiências de consumo. 
O omnichannel é uma estratégia focada no consumidor, na qual uma empresa está presente em diferentes canais online e offline, que atuam de forma complementar. $\mathrm{Na}$ definição de Verhoef et al. (2015), o omnichannel é "a gestão dos diferentes canais de vendas e pontos de contato disponíveis com o cliente de forma que a experiência do cliente entre os canais e o desempenho geral do canal sejam otimizados".

De acordo com um estudo de Pereira et al. (2020), os pesquisadores de marketing abordam o Omnichannel a partir de três ângulos de consumo diferentes: a experiência do consumidor e a jornada do cliente; investimentos em estratégias de negócios e em tecnologia; interação do marketing com outras áreas organizacionais. O uso da tecnologia se refere ao crescimento do uso de big data e a integração entre territórios, é um dos pilares do Omnichannel.

O novo consumidor integrou a preferência por uma experiência de compra positiva em seu comportamento, abrindo novos caminhos no processo que vai desde a pesquisa à aquisição na Internet ou em lojas físicas. Com a facilidade de se conectar à internet, ele fica praticamente online em tempo integral, portanto suas ações online têm impacto direto e imediato no canal offline, utilizado para encontrar, comprar e receber o produto (SOUZA, 2016).

\subsubsection{OMNICHANNEL NO MERCADO VAREJISTA}

A estratégia Omnichannel possui como característica uma gestão complexa e, para executá-la, as empresas, precisam melhorar suas habilidades analíticas em todos e diferentes tipos de canais, adotando o formato multicanal. (HOECKESFELD; MORAIS; MUSSI; SARQUIS, 2019).

Segundo Guissoni (2017), uma empresa que tem o Omnichannel como estratégia possui vantagens de negócio em relação àquelas que só trabalham com lojas físicas. Existem muitos pontos de contato que os consumidores podem acessar para concluir a jornada de compra, por exemplo, "na loja física, usando tecnologias de 
sensores que se comunicam de máquina para máquina para rastrear a jornada do cliente dentro da loja" (KOTLER; KARTAJAVA; SETIAWAN, 2016).

De acordo com Chen et al. (2018), existem várias posições Omnichannel. A principal delas diz respeito ao ponto de vista do consumidor em relação ao varejista. A abordagem centrada no consumidor propõe que o Omnichannel seja centrado nele e esclarece as considerações que moldam a receptividade do negócio, enquanto a abordagem centrada no varejista, estuda os fatores de habilitação e inibição da atividade do ponto de vista do consumidor.

Apesar das vantagens dos negócios Omnichannel, os desafios permanecem. Os negócios não são apenas afetados por problemas de consumo que se movem entre varejistas e canais, eles também enfrentam a concorrência de varejistas online. Além disso, a maior integração entre canais de comunicação online e offline levanta preocupações sobre segurança de dados, violações éticas e violações de privacidade (CHEN et al., 2018).

Para o estudo e, no caso de uma pequena empresa, são consideradas algumas vantagens da distribuição, como a possibilidade de a marca atingir todos os tipos de consumidores e não apenas uma fatia deles e o fato de o aumento da confiança do cliente poder gerar transações com valores mais elevados, construindo, assim, lealdade à marca e ganhando consumidores fiéis, que é uma das etapas mais importantes no crescimento de um negócio.

\section{MATERIAIS E MÉTODOS}

A metodologia é composta por métodos e ferramentas que serão aplicadas no desenvolvimento do estudo. Ela aborda tipos de pesquisas de acordo com a área escolhida. É possível defini-la quanto a natureza, quanto os meios e os fins, de acordo com classificações em relação a sua abordagem e o material a ser utilizado na pesquisa. 
De acordo com Marconi e Lakatos (2017), a metodologia compõe a realização de atividades de forma sistemática e racional, tendo o objetivo de contribuir para o desenvolvimento de conhecimentos importantes e notáveis, traçando um caminho a ser seguido, anunciando as correções para construções das decisões.

Desta forma, a metodologia aplicada na loja Shop Sukatão, foram pesquisas que propõe a solução dos problemas encontrados dentro da organização, de acordo com as necessidades detectadas, sendo realizada, portanto, uma pesquisa qualitativa, de campo e exploratória.

\subsection{PROCEDIMENTOS METODOLÓGICOS}

O procedimento metodológico é a explicitação dos métodos e instrumentos de pesquisa a serem aplicados. Na loja Shop Sukatão, foi realizado, incialmente, o levantamento de informações e coleta de dados, com a finalidade de implantar processos que ajudam no desenvolvimento operacional da organização, através de ferramentas e sistemas.

\subsubsection{QUANTO À NATUREZA}

Segundo Santos e Dias (2016), o estudo possui uma abordagem, semelhante a um planejamento, que visa demonstrar como os meios e os fins serão usufruídos de forma sistemática.

A natureza do presente estudo se baseia em uma metodologia crítica, neste trabalho com um estudo de caso, pois os dados levantados terão aplicação prática e serão de grande utilidade no gerenciamento das pequenas e grandes empresas.

O presente trabalho utiliza métodos de implementação de fatores internos para obter melhores resultados dentro da empresa. A pesquisa obteve uma abordagem qualitativa onde a coleta de informações foi essencial para o estudo de caso e para a escolha dos sistemas implementados. 


\subsubsection{QUANTO AOS FINS}

Para Casarin e Casarin (2012, p. 43), toda pesquisa independente de sua tipologia, é realizada visando atingir um objetivo.

Quanto aos fins a presente pesquisa será exploratória, proporcionando uma maior familiaridade com o problema, obtendo uma visão geral acerca da problemática encontrada no setor e planejando a ação necessária para mitigá-la.

\subsubsection{QUANTO AOS MEIOS}

Segundo Giraldi (2017), a pesquisa de campo é realizada no local onde ocorre o fenômeno estudado, identificando a satisfação dos usuários de uma empresa.

Quanto aos meios, a pesquisa será de campo, apresentando a coleta de dados, análise e observação para construir uma proposta significativa e que trará as devidas mudanças na organização.

\subsection{CARATERÍSTICAS DA EMPRESA}

A loja descrita pela Razão Social de S K R BEZERRA e Nome Fantasia de Shop Sukatão LTDA, encontra-se localizada na Avenida Oscar Borel, №: 102, Compensa. Suas atividades tiveram início no dia 07 de dezembro de 2017, sendo, desde então, atuante no ramo de variedades e utilidades. Atualmente, está presente no mercado a 3 anos, no entanto, a conclusão das obras no recinto onde localiza-se ainda não foi finalizada. A estrutura física possui em torno dos $3.000^{2}$ de área construída.

A loja possui apenas uma unidade, na qual, no atual momento, o proprietário não demonstra interesse em expandir ou aderir filiais, pelo fato de possuir outras lojas em outros segmentos.

Por tratar-se do ramo de variedades e de recorrente consumo, seus produtos tornam-se de grande procura, sendo assim, o Shop Sukatão conta com um público- 
alvo amplo de pessoas que buscam soluções para o dia a dia. Atualmente, a loja conta com uma equipe de 15 colaboradores, sendo em sua maioria mulheres.

\section{RESULTADOS E DISCUSSÕES}

No estudo realizado na loja Shop Sukatão Ltda, foi constatado pontos importantes em cada área funcional da organização, visto que que, através das informações coletadas, notou-se pontos críticos na área de produção e operações, como se observa no Gráfico 01: Medição de desempenho, que apresenta pontos de cada área funcional.

Gráfico 1: Média do Desempenho por área funcional

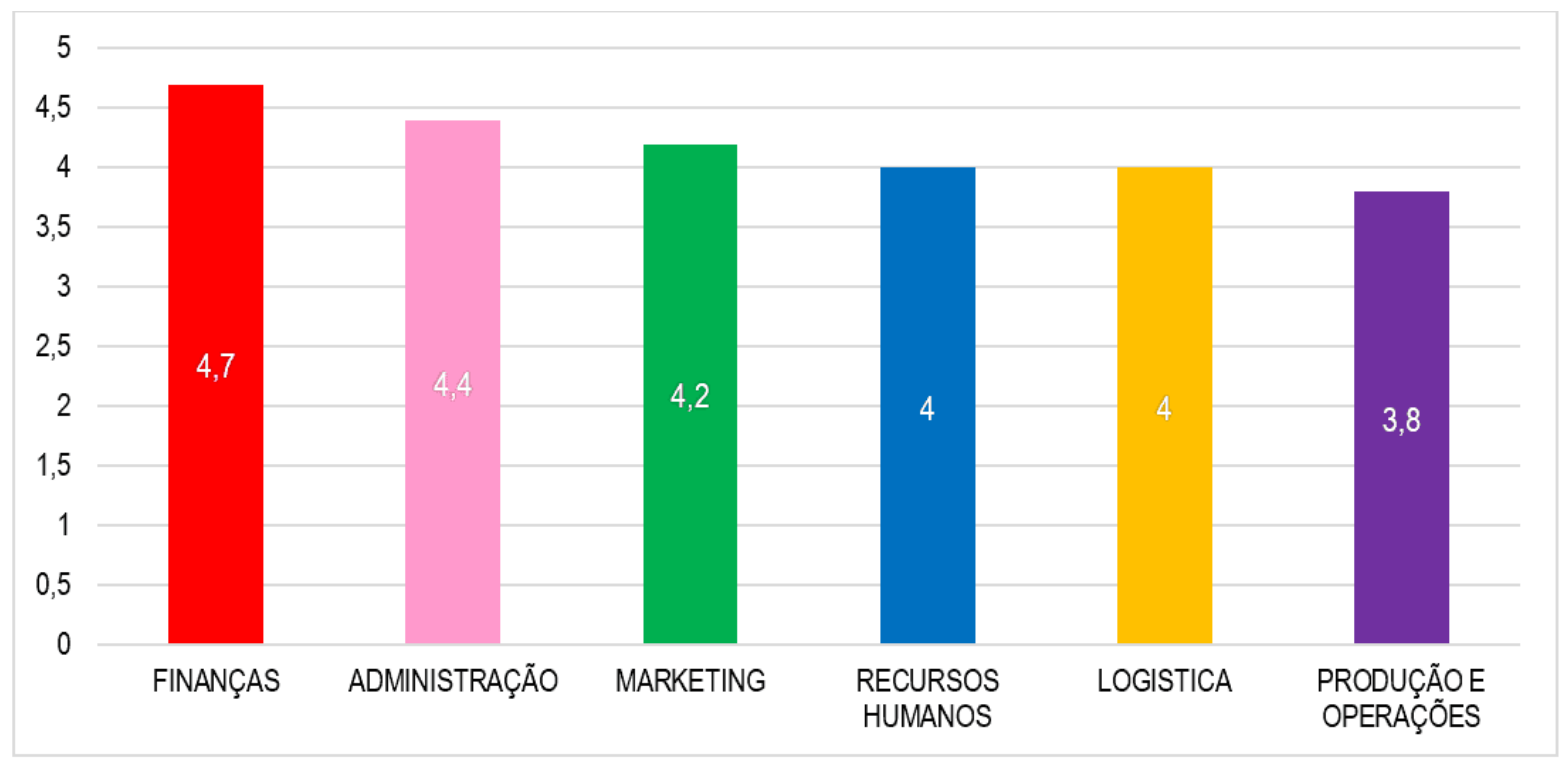

Fonte: Realizados pelos autores, 2021

Verifica-se que a empresa tem as áreas de finanças e administração com os melhores desempenhos; marketing e recursos humanos são áreas de desempenho médio. A área operacional é considerada a mais crítica, como se nota no quadro abaixo. 
Quadro 01: Operações.

\begin{tabular}{|c|c|c|c|c|c|c|}
\hline \multirow{2}{*}{\multicolumn{2}{|c|}{$\begin{array}{l}\text { ÁREA FUNCIONAL } \\
\text { OPERAÇÕES }\end{array}$}} & \multicolumn{5}{|c|}{ NÍVEL OU GRAU DE AVALIAÇÃO } \\
\hline & & $\begin{array}{l}\text { Ponto } \\
\text { muito } \\
\text { forte } \\
5\end{array}$ & $\begin{array}{l}\text { Ponto } \\
\text { forte } \\
4\end{array}$ & $\begin{array}{l}\text { Ponto } \\
\text { médio } \\
3\end{array}$ & $\begin{array}{l}\text { Ponto } \\
\text { fraco } \\
2\end{array}$ & $\begin{array}{l}\text { Ponto } \\
\text { muito } \\
\text { fraco } \\
1\end{array}$ \\
\hline 1 & $\begin{array}{l}\text { Disponibiliza-se equipamentos } \\
\text { adequados aos colaboradores }\end{array}$ & $\mathrm{x}$ & & & & \\
\hline 2 & $\begin{array}{l}\text { Ocorre-se frequência na compra de } \\
\text { produtos e materiais }\end{array}$ & & & $x$ & & \\
\hline 3 & $\begin{array}{l}\text { Observa-se a boa administração da } \\
\text { distribuição das mercadorias }\end{array}$ & & $\mathrm{x}$ & & & \\
\hline 4 & $\begin{array}{lr}\text { Efetua-se } & \text { controle } \\
\text { atendimentos } & \text { dos } \\
\text { diariamente } & \text { realizados }\end{array}$ & & & $x$ & & \\
\hline 5 & $\begin{array}{l}\text { Nota-se bom prazo de entrega dos } \\
\text { produtos }\end{array}$ & & & & $x$ & \\
\hline 6 & $\begin{array}{l}\text { Apresenta-se cálculos da satisfação } \\
\text { dos consumidores }\end{array}$ & & $\mathrm{x}$ & & & \\
\hline 7 & $\begin{array}{l}\text { Percebe-se preocupação em } \\
\text { atender os desejos dos clientes }\end{array}$ & & $\mathrm{x}$ & & & \\
\hline 8 & $\begin{array}{l}\text { Demonstra-se controle de entrada e } \\
\text { saída de produtos }\end{array}$ & $x$ & & & & \\
\hline 9 & $\begin{array}{l}\text { Verifica-se preocupação com a } \\
\text { manutenção dos equipamentos }\end{array}$ & $\mathrm{x}$ & & & & \\
\hline 10 & $\begin{array}{l}\text { Efetua-se pesquisa com clientes } \\
\text { para cálculo do desempenho }\end{array}$ & & & $\mathrm{x}$ & & \\
\hline
\end{tabular}


interno

\begin{tabular}{|l|l|l|l|l|l}
\hline TOTAL $(\Sigma)$ & 15 & 12 & 9 & 2 & 0 \\
\hline MÉDIA POR GRAU (POR COLUNA) & 1,5 & 1,2 & 0,9 & 0,2 & 0 \\
\hline DESEMPENHO DA ÁREA $(\Sigma)$ TOTAL & 3,8 & & & &
\end{tabular}

Fonte: Realizados pelos autores, 2021.

Identificou-se que a área de produção e operações apresentou pontos críticos, apresentando pontos fracos, que precisam ser analisados, como: problemas em relação ao prazo de entrega dos produtos.

\subsection{PLANEJAMENTO DE AÇÕES}

O planejamento de ação consiste em uma perspectiva de ação compartilhada por uma organização, um processo contínuo, composto de várias etapas que envolvem planos estratégicos para a tomada de decisões.

O plano de ação a ser seguido é o método $5 \mathrm{WH} 2$, onde se mostra 0 desenvolvimento de cada ação para transformar os resultados em todo o processo objetivo. Esse modelo traz, basicamente, o gerenciamento e busca facilidade no entendimento, através das definições de responsabilidade como: métodos, prazos, objetivos e recursos.

De acordo com Alves; Barbosa e Rodriguez (2019), pode-se dizer que o método $5 \mathrm{~W} 2 \mathrm{H}$ é utilizado pelas organizações para executar planos de ação de forma eficaz. Constata-se que o papel fundamental deste é solucionar as práticas que possibilitam identificar as atividades dentro da organização. $\mathrm{O}$ nome $5 \mathrm{~W} 2 \mathrm{H}$ vem das palavras: $\mathrm{O}$ que/What, quem/Who, quando/When, onde/Where, por quê/Why, Como/How, Quanto/How Much. 
Quadro 02: Ações interventivas

\begin{tabular}{|c|c|c|c|c|}
\hline Item & Ações interventivas & Cronologia & Duração & Custo \\
\hline 1. & $\begin{array}{l}\text { Implementação do método Balanced } \\
\text { Scorecard (BSC) }\end{array}$ & Out/2021 & 20 dias & $\begin{array}{l}\mathrm{R} \$ \\
1.500,00\end{array}$ \\
\hline 2. & $\begin{array}{l}\text { Implementação da ferramenta Material } \\
\text { Requirements Planning (MRP) }\end{array}$ & Nov/2021 & 15 dias & $\begin{array}{l}\mathrm{R} \$ \\
1.000,00\end{array}$ \\
\hline 3. & Implementar o método SCRUM & Nov/2021 & 2 meses & $\begin{array}{l}R \$ \\
1.500,00\end{array}$ \\
\hline 4. & Implementação da ferramenta 5'S & Dez/2021 & 2 meses & $\begin{array}{l}R \$ \\
1.500,00\end{array}$ \\
\hline 5. & Implementação do sistema Omnichannel & Dez/2021 & 1 mês & $\begin{array}{l}R \$ \\
2.500,00\end{array}$ \\
\hline \multicolumn{4}{|l|}{ Total } & $\begin{array}{l}R \$ \\
8.000,00\end{array}$ \\
\hline
\end{tabular}

Fonte: Realizados pelos autores, 2021.

Verifica-se no quadro 02 , as ações interventivas propostas visando resolver os problemas detectados na área mais crítica, para isto foi elaborado um plano estratégico definido por ações, cronogramas, duração e custo.

\subsubsection{IMPLEMENTAÇÃO DO MÉTODO BALANCED SCORECARD - BSC}

Ao implementar o Balanced Scorecard dentro da empresa Shop Sukatão, será melhor visualizado a estratégia da organização, bem como os serviços e os benefícios, alinhando, assim, as metas e objetivos dos departamentos, através do mapeamento e associação dos fatores de desempenho. Desse modo, os

RC: 101642

Disponível em: https://www.nucleodoconhecimento.com.br/administracao/metodos-e$\underline{\text { sistemas }}$ 
indicadores que refletem o processo produtivo interno trarão a capacidade de crescimento da empresa.

Desta forma, o departamento de operações irá identificar e realizar a integração do monitoramento dos elementos que irão alavancar o desempenho organizacional da empresa Shop Sukatão, alinhando, assim, as ações internas, a fim de que sejam implementadas as adequações de forma estratégica.

Quadro 03: Implementação do método Balanced Scorecard - BSC

Implementação do método Balanced Scorecard - BSC

\section{O que? Balanced Scorecard}

Por quê? Para frequência na compra de produtos e materiais

Onde? Na loja Shop Sukatão

Quando? na última semana de outubro 2021

Quem? Departamento de produção e operações

Como? Por meio de indicadores de frequência de compra que serão medidas a quantidade de vezes em que uma compra é realizada em determinado período.

quanto? $\mathrm{R} \$ 1.500,00$

Fonte: Realizados pelos autores, 2021.

O quadro 03 , traz o planejamento relacionado à frequência na compra de produtos e materiais, por meio de indicadores de frequência de compras, realizando medições da quantidade de vezes em que uma compra é realizada em determinado período e, ao fim, a proposta de implementação do método Balanced Scorecard-BSC, que tem como objetivo trazer melhorias para empresa, tendo um custo de $R \$ 1.500$. 


\subsubsection{IMPLEMENTAÇÃO DA FERRAMENTA MATERIAL REQUIREMENTS PLANNING (MRP)}

O processo de implementação do sistema de gestão MRP, conduz a organização a criar uma sequência de processos para os produtos, a fim de manter o mínimo de estoque possível, já que a empresa tem fatores críticos na frequência de compra dos produtos e materiais.

O MRP orientará as compras, com a finalidade de que estas sejam suficientes e necessárias para a produção e entrega do produto final, sem atrasos nas entregas, otimizando, assim, os recursos da manufatura, gerando, consequentemente, maior ganho nos custos e estoques da empresa. Assim, a gestão utilizará o sistema como um meio de planejamento para as compras de produção, onde o sistema MRP auxiliará para um menor custo de armazenagem.

Quadro 04: Implementação da ferramenta Material Requirements Planning (MRP)

Implementação da ferramenta Material Requirements Planning (MRP)

0 que? Material Requirements Planning (MRP)

Por quê? Para melhor prazo de entrega dos produtos

Onde? Na loja Shop Sukatão

Quando? na primeira semana de novembro 2021

Quem? Departamento de logística

Como? Por meio de implementação da ferramenta auxiliara na produção e entrega do produto final, não provocando atrasos nas entregas e assim otimizando os recursos da manufatura, causando maiores ganhos nos custos e estoques da empresa

quanto? $\mathrm{R} \$ 1.000,00$

Fonte: Elaborado pelos autores, 2021. 
A proposta desta ação, exposta no quadro acima, poderá auxiliar no prazo de entrega dos produtos, através da implementação de ferramentas que auxiliarão na produção e entrega do produto final, não provocando atrasos nas entregas e otimizando, assim, os recursos da manufatura, gerando maiores ganhos nos custos e estoques da empresa. A implementação desta ferramenta terá o custo de $R \$$ 1000,00 .

\subsubsection{IMPLEMENTAR O MÉTODO SCRUM}

Este programa deverá ser implantado para normatizar e padronizar a entrega de produtos da empresa, trazendo o benefício de segurança e tranquilidade ao cliente. O programa Scrum será instalado no setor operacional, especialmente no departamento de logística, pelos profissionais na área de tecnologia, que devem inseri-lo no software da loja, onde o sócio proprietário e os demais responsáveis pelo setor, poderão acompanhar a entrega em sua totalidade, ou seja, desde a saída da empresa ao destino, através do sistema instalado.

Quadro 05: Implementar o método SCRUM

Implementar o método SCRUM

\section{O que? Programa SCRUM}

Por quê? Para normatizar e padronizar a entrega de produtos

Onde? Na loja Shop Sukatão

Quando? Segunda semana de novembro a dezembro

Quem? Departamento de Tecnologia e Desenvolvimento Técnico

Como? Mediante a instalação do programa nos computadores da logística

quanto? $\mathrm{R} \$ 1.500$

Fonte: Elaborado pelos autores, 2021.

Quanto ao Programa Scrum, cujo método será altamente eficaz para normatizar a empresa na problemática referente a entrega de materiais, sua implementação 
possibilitará o acompanhamento do produto desde sua saída da empresa até a entrega ao consumidor final. Planeja-se que o custo para a aplicação deste método será de $R \$ 1.500,00$.

\subsubsection{IMPLEMENTAÇÃO DA FERRAMENTA 5'S}

Criada por especialistas japoneses durante a implantação do sistema Toyota de Produção, esta ferramenta tem como objetivo manter a empresa organizada em seus processos, analisando os pontos críticos e apresentando soluções de maneira prática e eficiente. É uma ferramenta que auxilia no alcance das metas e objetivos traçados pela empresa, pois trará clareza nos passos que deverão ser seguidos, controlando cada ação realizada.

Quadro 06: Implementação da ferramenta 5'S

Implementação da ferramenta 5'S

\begin{tabular}{|l|l|}
\hline O que? & ferramenta 5'S \\
\hline Por quê? & Para regularizar o sistema de entrega \\
\hline Onde? & Na loja Shop Sukatão \\
\hline Quando? & Início de dezembro \\
\hline Quem? & Departamento de Logística \\
\hline Como? & $\begin{array}{l}\text { Através de avaliação feita pelos clientes no recebimento de cada } \\
\text { entrega }\end{array}$ \\
\hline quanto? & $\mathrm{R} \$ 1.000 .00$ \\
\hline
\end{tabular}

Fonte: Elaborado pelos autores, 2021.

A implementação do método 5'S, é necessária para manter a empresa com os hábitos culturais organizados, como: limpeza do ambiente laboral, discernimento e atenção. Estima-se que o investimento para implantação será de $R \$ 1.000,00$. 


\subsubsection{SISTEMA OMNICHANNEL}

A proposta de implementação do sistema Omnichannel na empresa propõe a utilização da internet para remover as barreiras entre o online e o offline, integrando as operações na área de marketing, vendas e afins, gerando uma experiência nova ao cliente.

Quadro 07: Sistema Omnichannel

\begin{tabular}{|l|l|}
\hline \multicolumn{2}{|l|}{ Sistema Omnichannel } \\
\hline O que? & Programa SCRUM \\
\hline Por quê? & Melhorias nos canais de vendas \\
\hline Onde? & Na loja Shop Sukatão \\
\hline Quando? & O mês de dezembro \\
\hline Quem? & Departamento de Tecnologia e Desenvolvimento Técnico \\
\hline Como? & $\begin{array}{l}\text { Mediante a planos de ações, técnicas de análises de conteúdo, } \\
\text { implantações de estratégias e outros. }\end{array}$ \\
\hline quanto? & $\mathrm{R} \$ 2.500,00$ \\
\hline
\end{tabular}

Fonte: Elaborado pelos autores, 2021.

No quadro 07, podemos observar que fatores, como: a implementação do sistema Omnichannel, inclui melhorias nos canais de venda dentro da empresa, mediante a plano de ações, técnicas a serem aplicadas, estratégias para os funcionários desenvolverem seu desempenho diante do público-alvo, possuindo um custo de $\mathrm{R} \$$ 2.500,00 para implementação.

\section{CONSIDERAÇÕES FINAIS}

O presente estudo de caso realizou uma pesquisa de campo na loja de variedades Shop Sukatão. Através de análises iniciais, observou-se que havia setores que necessitavam de melhorias, assim, foi elaborado um estudo de caso direcionando, 
propondo a implementação de ferramentas e uso de sistemas para aprimorar as expectativas dos clientes e alavancar o negócio.

Foram coletadas informações importantes por meio de entrevistas, a fim de avaliar todas as áreas e identificar qual o problema da organização. Constatou-se que o setor operacional possuía um rendimento baixo, quando comparado aos demais setores presentes na organização.

Diante disto, o estudo teve como questão norteadora: como a estruturação dos fatores internos pode maximizar o desempenho operacional de uma empresa de varejo? Como resposta ao problema de pesquisa foram propostas um conjunto de ações interventivas, como: a implementação do método Balanced Scorecard (BSC); da ferramenta Material Requirements Planning (MRP); do método SCRUM; da ferramenta 5'S e do sistema Omnichannel. Estas ações visam proporcionar ganhos na eficiência operacional $e$, por consequência, maximizar os resultados organizacionais. Ao final, concretizamos o artigo com a missão de encontrar soluções que mais se adequassem as necessidades da empresa estudada.

Com base no estudo apresentado, ao implementar as ações, a empresa tem a possibilidade de lograr êxito em suas intervenções e obter maior eficiência em seu processo operacional, alcançando em toda a organização.

Entende-se que o artigo atingiu seu propósito no sentido de oferecer a empresa estudada soluções fundamentadas que podem proporcionar resultados.

\section{REFERÊNCIAS}

ALVES, V.; BARBOSA, L.; RODRIGUES, A. A utilização da metodologia 5W2H para o desenvolvimento de um plano de manutenção. Academia.edu. 2018. Disponível em:

https://www.academia.edu/42902742/A_UTILIZA\%C3\%87\%C3\%83O_DA_METODO LOGIA_5W2H_PARA_O_DESENVOLVIMENTO_DE_UM_PLANO_DE_MANUTEN $\%$ C3\% $87 \%$ C3\%83O

RC: 101642

Disponível em: https://www.nucleodoconhecimento.com.br/administracao/metodos-esistemas 
ARAÚJO, N. P. Sistema de multicanais: desafios enfrentados na migração da venda tradicional de varejo para o sistema omnichannel. Repositório Digital Fundação Getúlio Vargas. $2018 . \quad$ Disponível em: http://bibliotecadigital.fgv.br/dspace;/handle/10438/24243

CARDOSO, D. et al. Estudo de caso da aplicação do Balanced Scorecard numa Organização especializada na Área do Exercício, Saúde e Bem-Estar. Universidade de Lisboa faculdade motricidade humana avaliação de desempenho. 2016.

CARVALHO, E. B. de. Implementação do omnichannel nos processos de relacionamento com o cliente na empresa Magazine. 2020. Departamento de Ciências Administrativas, Centro de Ciências Sociais Aplicadas, Universidade Federal do Rio Grande do Norte, Natal, 2020. Disponível em: https://repositorio.ufrn.br/handle/123456789/35260 acesso: 07/10/2021.

CASARIN, E. de C. S.; CASARIN, S. J. Pesquisa Científica: da teoria à prática. Intersaberes, 2012.

CHAVES, L. C. S; BUZOLI, A. C.; A estratégia omnichannel no varejo brasileiro. 2020. Disponível em: http://www.fatecrp.edu.br/worktec/edicoes/2020-2/trabalhos/iiworktec-laura_chaves.pdf acesso: 08/10/2021.

DUARTE, L. O que é Scrum? Rio Grande do Sul: Luiz Tools. 2021. Disponível em: https: //www.luiztools.com.br/post/o-que-e-scrum/

LEÃO, T. 5S - O que é 5S e como implementar o programa na sua empresa. 2021. Nomus - Blog Industrial. Disponível em: https://www.nomus.com.br/blogindustrial/5s/

MARCONI, M. de A.; LAKATOS, E. M. Fundamentos de Metodologia científica. 8. ed. São Paulo: Atlas. 2017. 
MARTELLI, L.; DANDARO F. Planejamento e controle de estoque nas organizações. Revista Gestão Industrial. v. 11, n. 02: p. 170-185, 2015.

MENEGAT, O.; BORELLA, M. R. de C. Impacto dos conceitos do MRP no gerenciamento de estoques numa empresa metalúrgica do polo metalmecânico da Serra Gaúcha no Brasil. Revista Espacios. Vol. 38. (no 36) p. 11, 2017.

MENEZES, T. Gestão e Negócios: Logística - entenda a diferença entre o planejamento estratégico, tático e operacional. 2018. Blos Ipog. Disponível em: https://blog.jpog.edu.br/gestao-e-negocios/planejamento-estrategico-tatico-eoperacional/

NAPOLEÃO, B. M. Ferramentas da Qualidade: O glossário definitivo sobre as ferramentas da qualidade - 5S. 2018. Disponível em: https: //ferramentasdaqualidade.org/5s/>

RIBEIRO, A. C. R; LIGIA, L. G. Aprimorando o relacionamento com o cliente através de iniciativas omnichannel: estudos de caso no varejo brasileiro. Universidade Federal do Rio de Janeiro, 2020. Disponível em: http://repositorio.poli.ufrj.br/monografias/monopoli10031903.pdf Acesso: 08/10/2021.

SCWABER, K.; SUTHERLAND, J. Guia do Scrum: Um guia definitivo para o Scrum - As regras do Jogo. Scrum. Org and Scrumlnc, 2013. Disponível em: https: //scrumguides.org/docs/scrumguide/v1/Scrum-Guide-Portuguese-BR.pdf

SILVA, E. S. O balanced scorecard (BSC) e os indicadores de gestão. Vida Econômica. 2017. Disponível em: http://ivraria.vidaeconomica.pt/ebooks/1916-obalanced-scordecard-bsc-e-os-indicadores-de-gestao-9789897683428.html

Enviado: Outubro, 2021.

Aprovado: Novembro, 2021. 